\title{
Airway Pressure Release Ventilation and High-Frequency Oscillatory Ventilation: Potential Strategies to Treat Severe Hypoxemia and Prevent Ventilator-Induced Lung Injury
}

\author{
Francesca Facchin MD and Eddy Fan MD PhD
}

\author{
Introduction \\ Airway Pressure Release Ventilation \\ Basic Principles \\ Benefits and Disadvantages \\ Current Evidence \\ State of the Art and Future Prospects \\ High-Frequency Oscillatory Ventilation \\ Basic Principles \\ Benefits and Disadvantages \\ Current Evidence \\ State of the Art and Future Prospects \\ Future Directions and Conclusions
}

\begin{abstract}
Although lifesaving, mechanical ventilation can itself be responsible for damage to lung parenchyma. This ventilator-induced lung injury is especially observed in already injured lungs of patients with ARDS. New ventilatory approaches are needed to safely treat patients with ARDS, and recent studies have suggested the potential utility of open-lung strategies. Airway pressure release ventilation (APRV) and high-frequency oscillatory ventilation (HFOV) are 2 different openlung strategies that have been proposed to treat refractory hypoxemic respiratory failure while preventing ventilator-induced lung injury. APRV provides increased airway pressure as a potential recruitment mechanism and allows spontaneous breathing, with the potential benefits of decreased sedation, shorter duration of mechanical ventilation, and improvement in cardiac performance. HFOV delivers very small tidal volumes, to prevent volutrauma, at a constant (relatively high) mean airway pressure, thus avoiding atelectrauma. Despite their theoretical benefits, the utility of APRV and HFOV remains unproven and controversial for the routine treatment of ARDS in adult patients. This review is focused on the theoretical and practical aspects of APRV and HFOV, provides an overview of the current evidence, and addresses their possible use in the treatment of ARDS. Key words: acute respiratory distress syndrome; alternative mechanical ventilation; open lung; ventilator-induced lung injury; APRV; HFOV. [Respir Care 2015;60(10):1509-1521. ( 2015 Daedalus Enterprises]
\end{abstract}

Introduction

ARDS is a syndrome characterized by a heterogeneous distribution of diffuse alveolar damage, resulting in major

\footnotetext{
The authors are affiliated with the Interdepartmental Division of Critical Care Medicine, Department of Medicine, University of Toronto, and the Department of Medicine, University Health Network and Mount Sinai Hospital, Toronto, Ontario, Canada.

Dr Fan presented a version of this paper at the 30th New Horizons in Respiratory Care Symposium: Approaches to Refractory Hypoxemic Re-
}

losses of aerated lung tissue. The relatively unaffected lung that is available for gas exchange becomes small

spiratory Failure: Ventilate, Oscillate, Cannulate, or Rotate of the AARC Congress 2014, held December 9-12, 2014, in Las Vegas, Nevada.

The authors have disclosed no conflicts of interest.

Correspondence: Eddy Fan MD PhD, Toronto General Hospital, 585 University Avenue, PMB 11-123, Toronto, Ontario M5G 2N2, Canada. E-mail: eddy.fan@uhn.ca.

DOI: $10.4187 /$ respcare. 04255 


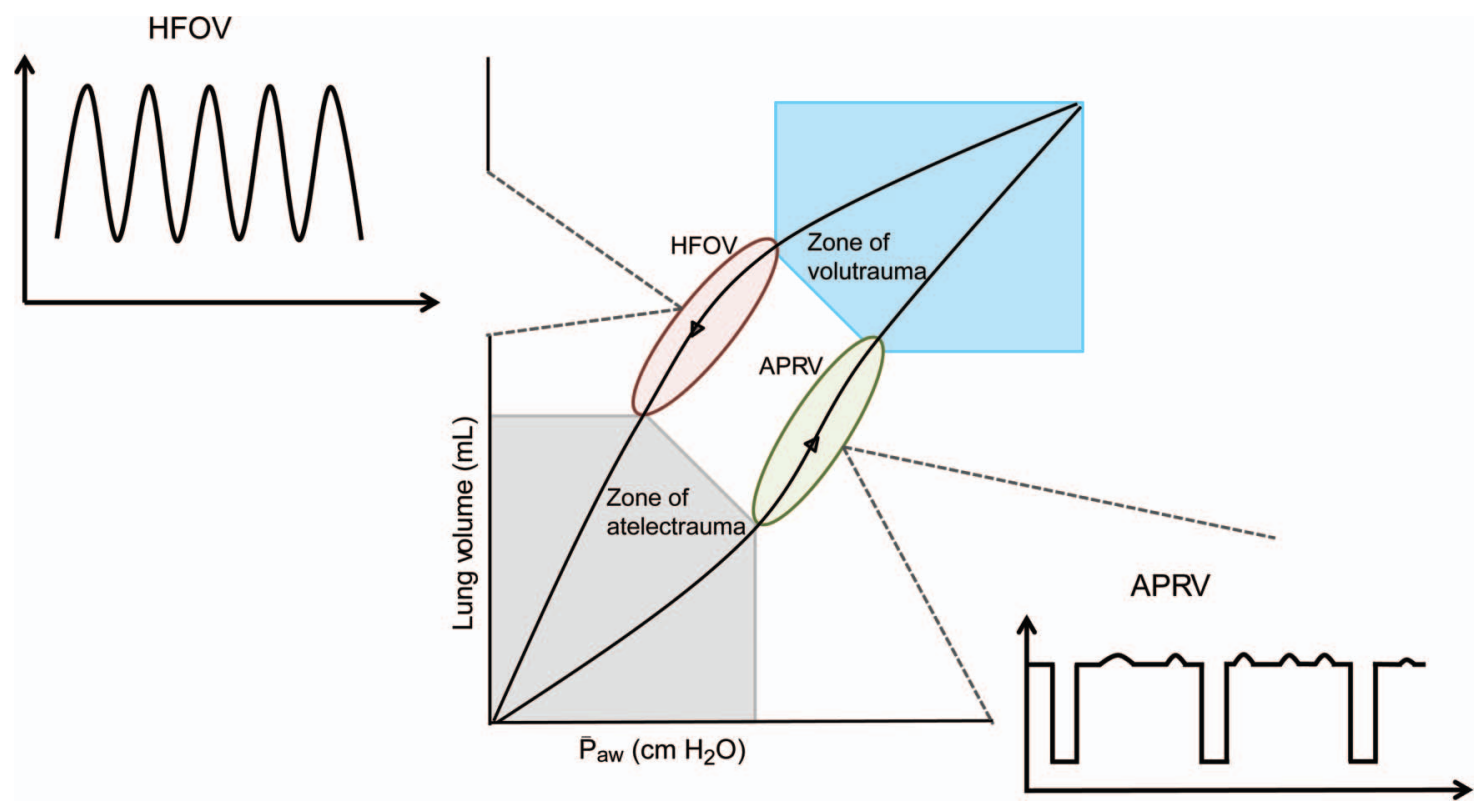

Fig. 1. Pressure-volume curve of the lung during inflation and deflation. The zones of volutrauma and atelectrauma are shown at high and low pressure and volume, respectively. Note that airway pressure release ventilation (APRV) occurs on the inspiratory limb of the curve, whereas high-frequency oscillatory ventilation (HFOV) occurs on the expiratory limb (following a recruitment maneuver). $\bar{P}_{\text {aw }}=$ mean airway pressure. ${ }^{13}$

(baby lung) and very susceptible to the excessive stress and strain applied by mechanical ventilation, so, although lifesaving, it can itself cause or worsen lung injury. ${ }^{1,2}$ This is generally referred to as ventilator-induced lung injury (VILI). ${ }^{3,4}$ VILI can be caused by excessive tidal volume $\left(\mathrm{V}_{\mathrm{T}}\right.$; volutrauma) and repetitive opening and closing of alveoli (atelectrauma). Both mechanisms lead to the release of inflammatory mediators, resulting in a local and systemic inflammatory response (biotrauma). Volutrauma, atelectrauma, and biotrauma due to mechanical ventilation contribute to the development of multiple-organ dysfunction syndrome and death in patients with ARDS. . $^{5}$

A number of possible strategies have been proposed to avoid or reduce VILI, but a safe limit for mechanical ventilation and the optimal ventilatory strategy in ARDS have not been determined yet. A pressure- and volumelimited ventilatory approach helps to minimize the injury due to the stretch of lung units in inspiration. ${ }^{8}$ This strategy led to a significant reduction in mortality in a landmark multi-center trial performed by the ARDS Network. ${ }^{9}$ However, recent evidence suggests that in subjects with more severe ARDS (ie, greater amounts of non-aerated lung), limiting $\mathrm{V}_{\mathrm{T}}$ to $6 \mathrm{~mL} / \mathrm{kg}$ of predicted body weight may be not sufficient to avoid tidal overdistention and VILI, and lower $\mathrm{V}_{\mathrm{T}}$ may be safer in these subjects. ${ }^{10}$ The cyclic collapse and reopening of alveoli could be reduced by the use of an open-lung strategy. ${ }^{11}$ The application of PEEP during conventional ventilation can improve oxygenation, prevent cyclic end-expiratory collapse, and increase end-expiratory lung volume through alveolar re- cruitment. ${ }^{12}$ Other potentially useful open-lung strategies include airway pressure release ventilation (APRV) and high-frequency oscillatory ventilation (HFOV) (Fig. 1).

HFOV also has the potential benefit of delivering very low $\mathrm{V}_{\mathrm{T}}$. Up until now, these modes of ventilation have been used mainly in 2 clinical settings: (1) early ARDS, as the primary mode of lung-protective ventilation; and (2) rescue situations, in which conventional mechanical ventilation fails to induce adequate oxygenation and ventilation. This review focuses on the theoretical and practical aspects of APRV and HFOV and also examines the clinical evidence supporting their use for the treatment of ARDS in adult patients.

\section{Airway Pressure Release Ventilation}

\section{Basic Principles}

APRV was first proposed by Downs and Stock in 198714 and represents a pressure-limited time-cycled ventilatory mode, available on commercial ventilators with active exhalation valves. APRV switches between 2 pressure levels, $\mathrm{P}_{\text {high }}$ and $\mathrm{P}_{\text {low }}$ (Fig. 2). ${ }^{15}$

Conceptually, APRV applies a continuous airway pressure similar to CPAP, with the difference that, in APRV, there is an intermittent reduction in airway pressure (to $\mathrm{P}_{\text {low }}$ ). Compared with CPAP, APRV provides better $\mathrm{CO}_{2}$ clearance. The distinction between APRV and biphasic intermittent positive airway pressure (BIPAP) is not al- 


\section{APRV and HFOV to Treat Severe Hypoxemia and Prevent VILI}

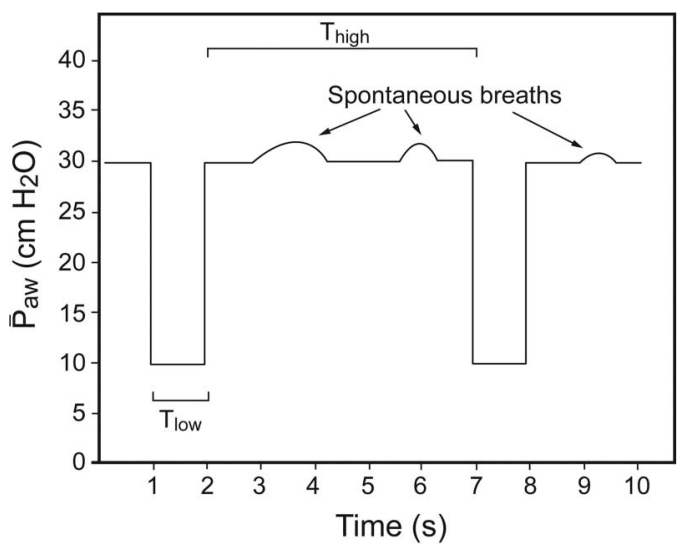

Fig. 2. Pressure-time for airway pressure release ventilation and control variables. $\mathrm{T}_{\text {high }}=$ inflation time; $\mathrm{T}_{\text {low }}=$ deflation time; $\overline{\mathrm{P}}_{\mathrm{aw}}=$ mean airway pressure.

ways clear-cut. Compared with BIPAP, APRV is more frequently set on extreme inverse ratios to improve refractory hypoxemia. However, if the same inspiratory-expiratory ratio is adopted, virtually no differences exist between APRV and BIPAP.

The clinician can set $\mathrm{P}_{\text {high }}$ to provide an inflation volume of $4-8 \mathrm{~mL} / \mathrm{kg}$ of predicted body weight, whereas $\mathrm{P}_{\text {low }}$ can be set between 0 and $8 \mathrm{~cm} \mathrm{H}_{2} \mathrm{O}$. The inflation time $\left(\mathrm{T}_{\text {high }}\right)$ may be set between 4 and $6 \mathrm{~s}$, and the deflation time $\left(\mathrm{T}_{\text {low }}\right)$ between 0.2 and $0.8 \mathrm{s.}^{16}$ The degree of support depends on the frequency of inflations and deflations. The active exhalation valve allows spontaneous breathing throughout the entire ventilatory cycle, with most of the spontaneous breaths occurring during $\mathrm{T}_{\text {high }}$ (given its longer duration). A longer inflation time results in greater potential for alveolar recruitment. The mean airway pressure $\left(\overline{\mathrm{P}}_{\mathrm{aw}}\right)$ is controlled by the combination of $\mathrm{P}_{\text {high }}, \mathrm{P}_{\text {low }}$, and $\mathrm{T}_{\text {high }}: \mathrm{T}_{\text {low }}$ ratio and can be calculated as: $\overline{\mathrm{P}}_{\text {aw }}=\left(\mathrm{P}_{\text {high }} \times \mathrm{T}_{\text {high }}+\mathrm{P}_{\text {low }} \times \mathrm{T}_{\text {low }}\right) /\left(\mathrm{T}_{\text {high }}+\mathrm{T}_{\text {low }}\right)$.

Oxygenation is determined by the $\mathrm{F}_{\mathrm{IO}_{2}}$ and $\mathrm{T}_{\text {high }}$. $\mathrm{T}_{\text {high }}$ should be set to provide the longest inspiration time, without impairing the necessary minute ventilation, while maintaining an alveolar pressure (plateau pressure) of $<35 \mathrm{~cm}$ $\mathrm{H}_{2} \mathrm{O}$. Ventilation is determined by the driving pressure $\left(\mathrm{P}_{\text {high }}-\mathrm{P}_{\text {low }}\right)$ and breathing frequency. To improve $\mathrm{CO}_{2}$ removal, 2 strategies are possible. $\mathrm{P}_{\text {high }}$ can be increased and $\mathrm{T}_{\text {high }}$ decreased, with consequent high ventilation volumes and no significant changes in the $\overline{\mathrm{P}}_{\mathrm{aw}}$. Alternatively, $\mathrm{T}_{\text {low }}$ (release time) can be decreased by increments of $0.05-0.1 \mathrm{~s}$. It is also possible to reduce the patient sedation to increase their active contribution to minute ventilation. ${ }^{17}$ The inverse ratio, created by a long $\mathrm{T}_{\text {high }}$ compared with a short $\mathrm{T}_{\text {low }}$, supports spontaneous breathing during the inflation period, but may lead to intrinsic PEEP. ${ }^{18,19}$ Because evidence does not support the use of intrinsic rather than extrinsic PEEP, ${ }^{19}$ the former should be avoided by adjust- ing $\mathrm{T}_{\text {low }}$, thus allowing complete expiration to the resting lung volume (ie, allowing expiratory flow to reach zero).

Some commercial ventilators allow the use of additional pressure support to facilitate spontaneous respiratory efforts, but the effectiveness of such a strategy has never been systematically evaluated. In some devices, the inflation phase can be also synchronized with the respiratory efforts, thus increasing the patient's comfort.

$\mathrm{P}_{\text {high }}$ and $\mathrm{P}_{\text {low }}$ in APRV can be considered to be comparable, respectively, to the inspiratory pressure and PEEP of pressure controlled ventilation. Given the long $\mathrm{P}_{\text {high }}$ compared with the short $\mathrm{P}_{\text {low }}$, without any spontaneous respiratory effort (eg, when the patient is sedated and/or paralyzed), APRV is similar to conventional pressure controlled inverse-ratio ventilation, a strategy that generated some enthusiasm on its initial introduction due to the prompt improvement in oxygenation that it could achieve. However, the improvements in oxygenation with pressure controlled inverse-ratio ventilation are due to higher airway pressure and intrinsic PEEP, with increased risk of volutrauma, need for sedation, and deleterious effects on the cardiovascular system. Therefore, inverse-ratio ventilation has no place in the routine management of ARDS, ${ }^{20}$ and thus, APRV (with an inverse inspiratory-expiratory ratio) should be considered only in patients with preserved spontaneous breathing.

\section{Benefits and Disadvantages}

The potential benefits of APRV are mostly linked to spontaneous breathing and include: (1) better patient-ventilator synchrony, with consequent improvement in patient comfort; (2) improvement in ventilation/perfusion matching by promoting a more physiological gas distribution to the nondependent lung regions ${ }^{21-24}$; (3) a potential decrease in sedation and analgesia ${ }^{25}$; and (4) improvement in cardiac performance, secondary to the reduction in patient sedation and to the decrease in intrathoracic and right atrial pressures. $^{23,16,26}$ APRV-associated improvements in oxygenation seem to be particularly relevant in morbidly obese surgical patients with already compromised lung function, reduced lung volumes and compliance, and muscle inefficiency. In this group of patients, the continuous positive pressure achieved with APRV maintains lung recruitment while limiting overdistention. At the same time, the decrease in sedation facilitates spontaneous breathing and patient interaction with the environment and reduces pulmonary complications. ${ }^{27}$ Given that most of the benefits of APRV are related to spontaneous breathing, this method is usually not indicated for patients who require deep sedation and neuromuscular blockade.

Even though the use of neuromuscular blocking agents is still controversial in critically ill patients, ${ }^{28}$ recent evidence suggests that induced paralysis within the first $48 \mathrm{~h}$ 
of mechanical ventilation improves the survival of patients with severe ARDS. ${ }^{29}$ The use of APRV in patients with ARDS might be considered later in the clinical course, when spontaneous breathing may result in a better distribution of ventilation and aeration to the dependent lung regions, contributing to improve arterial oxygenation.

In support of this idea, one study demonstrated that, despite identical ventilator settings, spontaneous breathing had different effects on ventilatory strategies depending on the type of synchronization. ${ }^{30}$ Indeed, compared with a partially or fully synchronized mode, a non-synchronized mode such as APRV has been shown to be more protective in limiting lung stress and strain. When associated with spontaneous efforts, APRV was associated with low- $\mathrm{V}_{\mathrm{T}}$ ventilation and with a more physiological variability of $\mathrm{V}_{\mathrm{T}}$. Therefore, whenever a lung-protective strategy has to be chosen, it is advisable to consider the specific effects of each different method on $\mathrm{V}_{\mathrm{T}}$ and its variability. Relative contraindications to APRV include patients with obstructive lung disease (asthma exacerbations or COPD), ${ }^{31}$ and it has never been rigorously investigated in patients with neuromuscular disease.

\section{Current Evidence}

In the last 3 decades, there have been a few clinical trials comparing APRV and conventional mechanical ventilation in subjects with ARDS, often with discordant results (Table 1). Putensen et al ${ }^{23}$ compared APRV and pressure controlled ventilation in a randomized controlled trial (RCT) and demonstrated that APRV was associated with improved cardiopulmonary performance, fewer ventilator and ICU days, and improved arterial oxygenation. Varpula et $\mathrm{al}^{32}$ compared APRV and synchronized intermittent mandatory ventilation with pressure support and did not find significant differences in clinically relevant outcomes. However, there was significant improvement in oxygenation with APRV, especially when used with prone positioning. Both of these studies aimed to determine the response of oxygenation to APRV with spontaneous breathing. Although $\mathrm{P}_{\mathrm{aO}_{2}} / \mathrm{F}_{\mathrm{IO}_{2}}$ has been frequently used to predict clinical outcomes, it has not been found to be an independent predictor of mortality in many ARDS studies. ${ }^{39}$ For instance, subjects in the ARDS Network trial assigned to the lower- $\mathrm{V}_{\mathrm{T}}$ group had lower mortality compared with those treated with higher $\mathrm{V}_{\mathrm{T}}$ even though their oxygenation was worse during the first few days of therapy. ${ }^{9}$ The design of clinical trials for novel ARDS ventilatory modes (eg, APRV or HFOV) is complex and needs the identification of other clinical outcomes to predict mortality. In particular, to determine the effectiveness of protective ventilatory strategies, a combination of clinical and biological parameters could be more useful markers than the assessment of blood oxygenation. ${ }^{39}$
González et $\mathrm{al}^{36}$ conducted a retrospective analysis in a multi-center international study. They used a propensity score to match subjects who received APRV/BIPAP with continuous mandatory ventilation and found no differences in major clinical outcomes (ie, mortality, days of mechanical ventilation, ICU stay). Conversely, in a study on APRV in adult trauma subjects, Maxwell et $\mathrm{al}^{37}$ showed a nonsignificant improvement in ventilator days, ICU stay, and ventilator-associated pneumonia compared with low- $\mathrm{V}_{\mathrm{T}}$ ventilation. These results might be explained by significantly worse baseline parameters in the APRV group (APACHE II [Acute Physiology and Chronic Health Evaluation II] 20.5 vs 16.9) in the study. However, in another retrospective study, Maung et al ${ }^{38}$ found a statistically significant increase in ventilator days (20 vs 11$)$, a lower nadir of $\mathrm{P}_{\mathrm{aO}_{2}} / \mathrm{F}_{\mathrm{IO}_{2}}(187$ vs $243 \mathrm{~mm} \mathrm{Hg}$ ), and a higher tracheostomy rate (44\% vs $28 \%$ ) in APRV subjects compared with the population on continuous mandatory ventilation. Given these conflicting results and the paucity of available data, rigorous clinical trials on larger populations are needed to clarify the potential efficacy of APRV in adult patients with ARDS.

\section{State of the Art and Future Prospects}

The treatment of patients with ARDS is rarely based on a single ventilatory strategy. APRV is a mode of ventilation that can be considered in patients with severe ARDS. In specific disease phases, the use of alternative modes of mechanical ventilation can indeed be useful to improve outcomes (ie, weaning from mechanical ventilation). APRV has been shown to be a safe ventilatory strategy especially in patients with ARDS: unsupported spontaneous breathing during ARDS maximizes and maintains lung recruitment with low peak pressure, thus avoiding overdistention. However, some investigators reported a limited use of this mode as well as other pressure controlled techniques, including BIPAP, perhaps because of the lack of clarity in defining criteria. As reported above, BIPAP and APRV are similar in allowing unsupported spontaneous breathing over a level of CPAP. A recent systematic review to identify the best defining criteria of these ventilatory modes found substantial inconsistencies in their definitions. ${ }^{40}$ The ambiguity concerning the definition of such modalities may thus impair their use in clinical practice. Therefore, the use of generic names describing the type of ventilator setting should be considered to help clinicians understand the similarities and differences in these various strategies.

Clinical and animal studies demonstrate an improvement in gas exchange, cardiac output and systemic blood flow. ${ }^{19,21,41}$ Spontaneous breathing during APRV also results in dependent lung region recruitment without the need to raise applied airway pressure. ${ }^{16}$ APRV also in- 


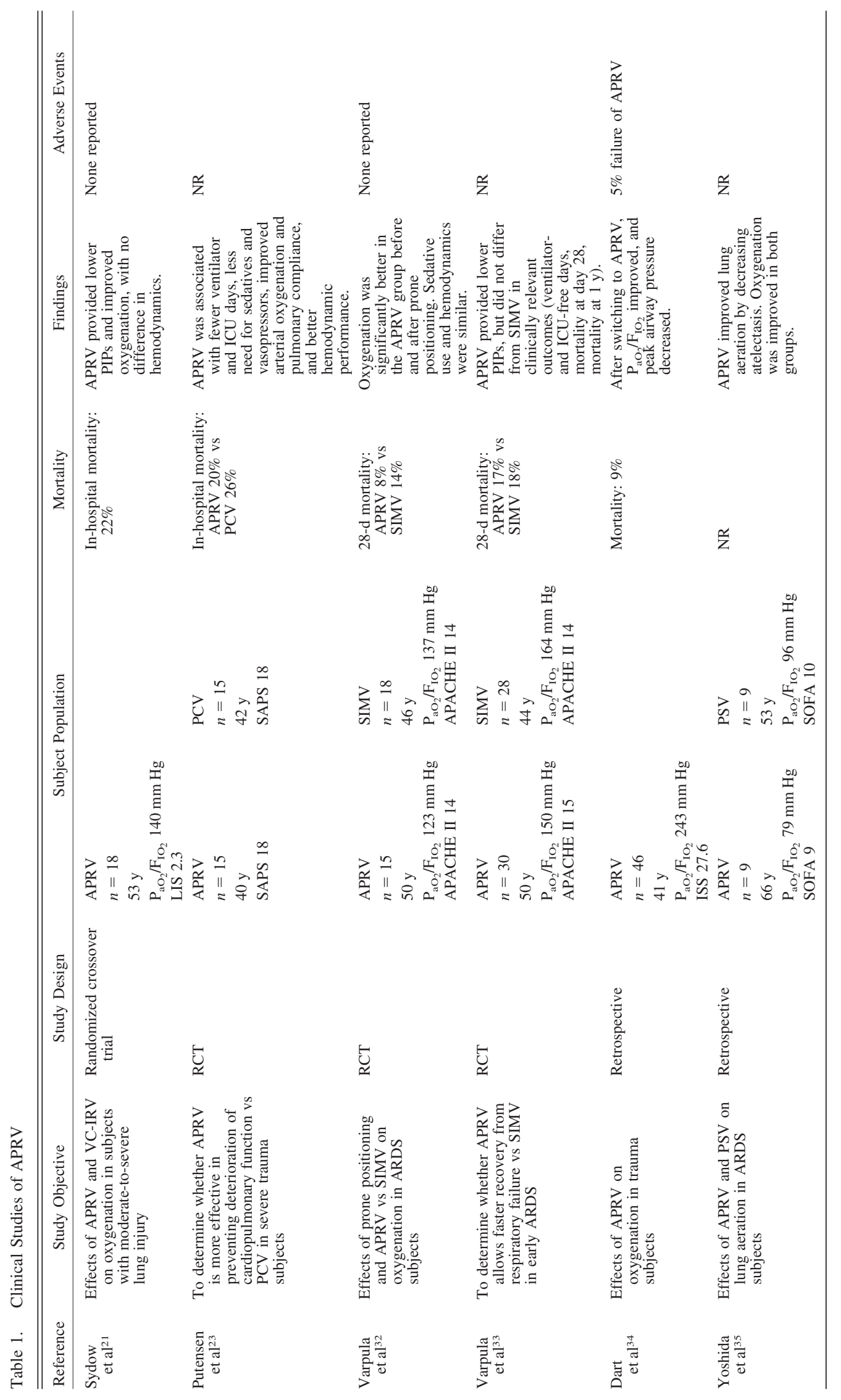




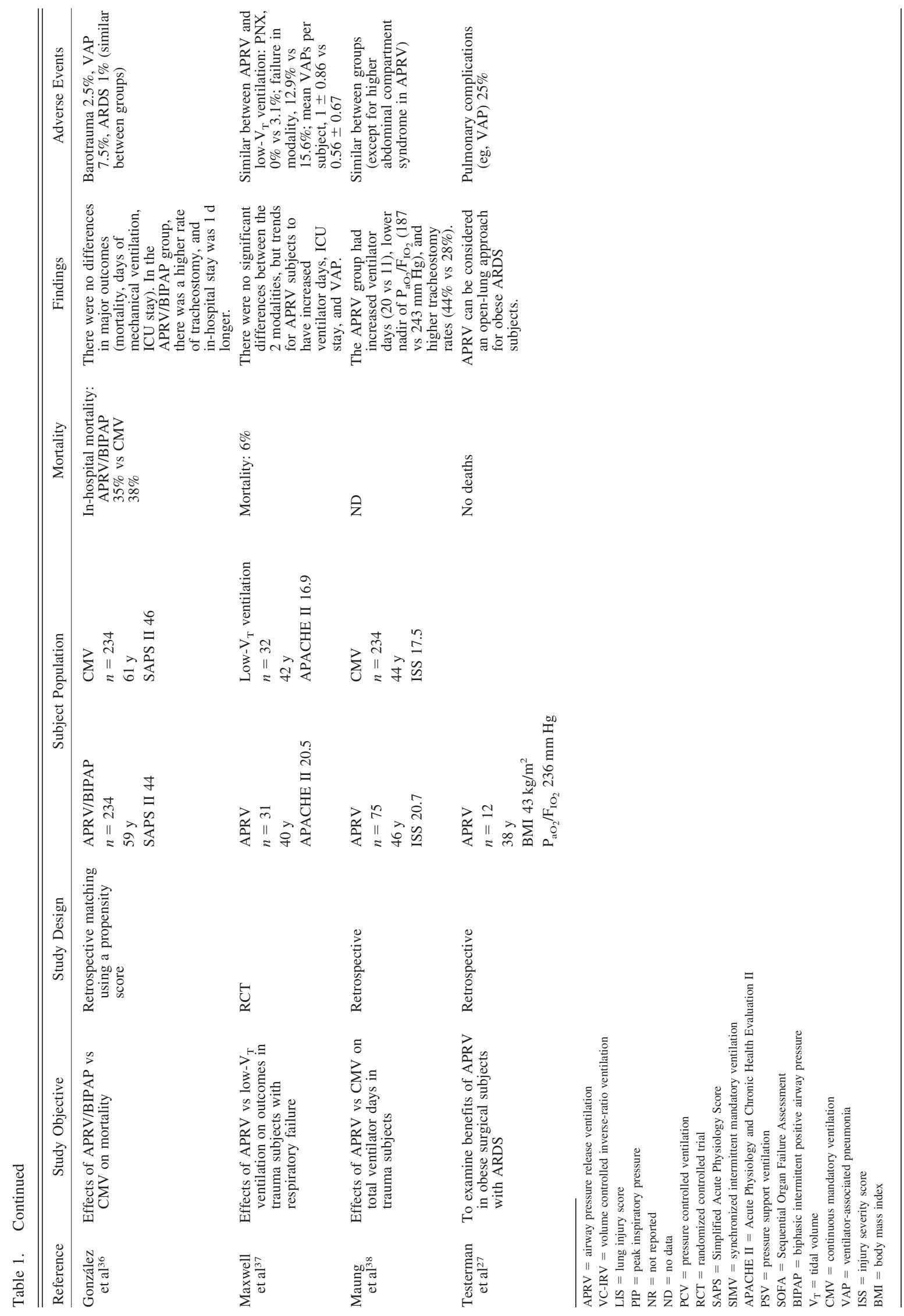



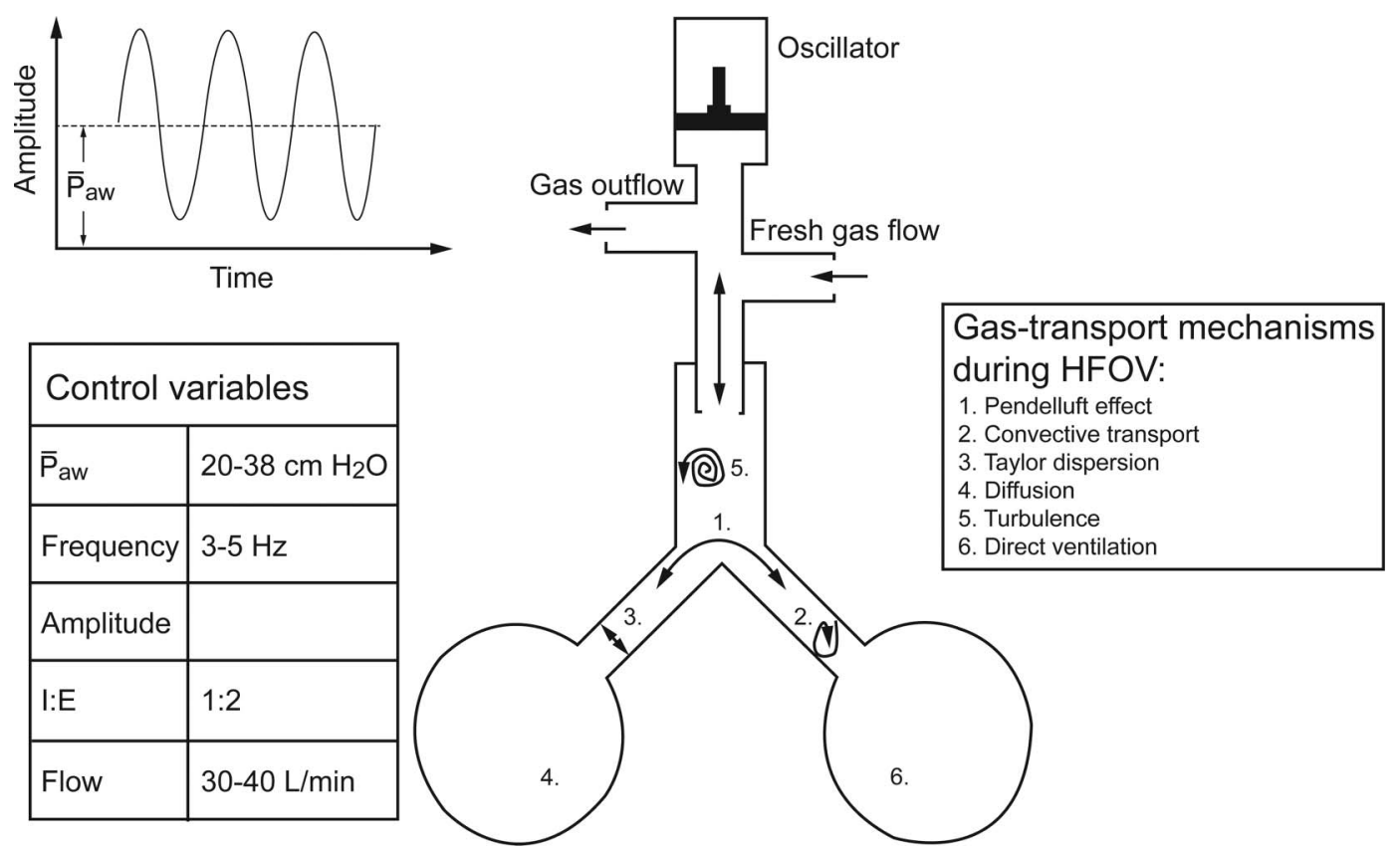

Fig. 3. High-frequency oscillatory ventilation (HFOV), schematic representation of the oscillator circuit, the control variables and the mechanisms involved. $\overline{\mathrm{P}}_{\mathrm{aw}}=$ mean airway pressure; I:E = inspiratory-expiratory ratio.

creases patient-ventilator synchrony, with potentially decreased sedation and analgesia requirements. ${ }^{25}$ Notably, the possible reduction in sedation is still debated, as one study failed to find any differences in its use between subjects treated with either APRV or standard ventilatory strategies. ${ }^{37}$ There have been few RCTs evaluating APRV, and those that have been published had small sample sizes, did not compare APRV with best practices in conventional mechanical ventilation for ARDS, and yielded conflicting results on subject outcomes. Large RCTs are needed to better understand the effect of APRV on survival, ventilator-free days, ICU stay, and longer-term outcomes in subjects with ARDS.

\section{High-Frequency Oscillatory Ventilation}

\section{Basic Principles}

HFOV is an alternative method of ventilation first developed for the treatment of respiratory distress syndrome in neonates. ${ }^{42,43} \mathrm{HFOV}$ uses an oscillatory pump to deliver active inspiration and expiration, producing pressure oscillations around a relatively constant $\overline{\mathrm{P}}_{\mathrm{aw}}$. It delivers very low $\mathrm{V}_{\mathrm{T}}$ at high breathing frequencies and is designed to recruit and maintain adequate end-expiratory lung volumes, attenuate atelectrauma, and improve oxygenation. Thus, HFOV can be considered an ideal way to prevent VILI (ie, prevention of volutrauma with low $\mathrm{V}_{\mathrm{T}}$, prevention of cyclic end-expiratory collapse with constant $\overline{\mathrm{P}}_{\mathrm{aw}}$ ) in patients with ARDS.
The typical ventilatory variables set by clinicians are the $\overline{\mathrm{P}}_{\mathrm{aw}}$, breathing frequency, pressure amplitude, $\mathrm{F}_{\mathrm{IO}_{2}}$, inspiratory-expiratory ratio, and circuit bias flow (Fig. 3 ). $\overline{\mathrm{P}}_{\mathrm{aw}}$ can be set from 20 to $38 \mathrm{~cm} \mathrm{H}_{2} \mathrm{O}$ (usually according to oxygenation), oscillation frequency normally varies between 3 and $15 \mathrm{~Hz}$, and pressure amplitude is set at $\sim 90 \mathrm{~cm} \mathrm{H}_{2} \mathrm{O}$. The pressure amplitude measured at the proximal endotracheal tube is attenuated by the system impedance, and only $5-16 \%$ of this value is developed in the trachea. ${ }^{44}$ The initial $\mathrm{F}_{\mathrm{IO}_{2}}$ is usually set at 1.0 , and the inspiratoryexpiratory ratio at $1: 2$. The circuit bias flow is generally set near the maximum of 30-40 L/min to ensure adequate $\mathrm{CO}_{2}$ clearance and maintenance of the $\overline{\mathrm{P}}_{\mathrm{aw}}$. With these settings, the delivered $\mathrm{V}_{\mathrm{T}}$ is often below the anatomic dead space $\left(1-3 \mathrm{~mL} / \mathrm{kg}\right.$ of predicted body weight). ${ }^{45}$ Some authors recommend increasing the oscillation frequency as much as possible to minimize $\mathrm{V}_{\mathrm{T}}$ and alveolar cyclic pressures. ${ }^{47}$ Before initiating HFOV, a recruitment maneuver is often recommended to reopen collapsed alveoli, allowing the relatively high $\overline{\mathrm{P}}_{\mathrm{aw}}$ to maintain the recruited lung. 46,47

Once HFOV is started, the ventilator settings can be adjusted to optimize oxygenation and/or $\mathrm{CO}_{2}$ elimination. Oxygenation is controlled primarily by the $\overline{\mathrm{P}}_{\mathrm{aw}}$ and $\mathrm{F}_{\mathrm{IO}_{2}}$, whereas $\mathrm{CO}_{2}$ clearance is regulated by the oscillation frequency and amplitude or power $(\Delta \mathrm{P})$. To improve the elimination of $\mathrm{CO}_{2}$, the $\Delta \mathrm{P}$ should be increased to maximum before decreasing the oscillation frequency. Deflation of the endotracheal tube cuff (eg, reduction in cuff pressure by $5 \mathrm{~cm} \mathrm{H}_{2} \mathrm{O}$ ) may also be useful to facilitate $\mathrm{CO}_{2}$ clearance. ${ }^{48}$ Considering the small $\mathrm{V}_{\mathrm{T}}$ delivered, direct 
alveolar ventilation cannot be the sole mechanism involved in gas transport during HFOV. ${ }^{49,50}$ The following mechanisms, among others, may also improve ventilation/perfusion mismatch: (1) pendelluft effect (ie, movement of gas between lung regions with different compliance and time constants); (2) convective transport of gases (ie, transport of gas into the alveoli secondary to the vacuum left after the absorption of oxygen into the capillaries); (3) longitudinal (Taylor) dispersion (ie, passage of oxygenated gas from the rapid central jet into the deeper bronchial tree); (4) augmented molecular diffusion near the alveolar-capillary membrane; and (5) turbulence in the large airways, causing enhanced mixing.

\section{Benefits and Disadvantages}

HFOV can be considered an effective lung-protective strategy for its ability to ventilate and oxygenate with very low $\mathrm{V}_{\mathrm{T}}$ especially at higher frequencies. Low $\mathrm{V}_{\mathrm{T}}$ enables the safe ventilation of the small and heterogeneously damaged lungs of patients with ARDS, preventing volutrauma. At the same time, the application of positive pressure reduces the shear stress caused by the repetitive cyclic opening and collapse of lung units, thus avoiding de-recruitment. Importantly, even very high pressures may not be dangerous if applied for a very short time. ${ }^{51,52} \mathrm{HFOV}$ with $\overline{\mathrm{P}}_{\mathrm{aw}}$ significantly higher than generally accepted plateau pressures but with minimal cyclic stretch may have a larger margin of safety in inducing lung recruitment while avoiding alveolar overdistention. ${ }^{53}$ In this context, the use of recruitment maneuvers may help to reopen atelectatic alveoli before applying a high $\overline{\mathrm{P}}_{\mathrm{aw}}$.

Furthermore, the short inspiratory time creates a more homogeneous distribution of ventilation compared with conventional mechanical ventilation. ${ }^{54,55}$ The presence of several mechanisms of gas transport during HFOV leads to an improvement in ventilation/perfusion matching and, ultimately, blood oxygenation. The pendelluft effect is particularly important for the lung units with long time constants and for those alveoli otherwise not reached by the primary HFOV $\mathrm{V}_{\mathrm{T}}$. The convective exchange is important for ventilation of the large or medium airways. The longitudinal dispersion is important for $\mathrm{CO}_{2}$ elimination, and molecular diffusion is one of the dominant forms of gas transport near the alveolar capillary membrane..$^{50}$ Finally, active expiration may play a beneficial role in HFOV, contributing to the prevention of gas trapping and allowing optimal ventilation and carbon dioxide clearance.

There are a number of potential risks with HFOV. These can be summarized as: (1) the occasional need for heavy sedation and/or neuromuscular blockade, (2) a possible significant reduction in cardiac preload, (3) difficult application in centers with little experience, (4) unavailability of transport ventilators, (5) possible loss of $\overline{\mathrm{P}}_{\mathrm{aw}}$ (and subsequent de-recruitment) during circuit disconnections, (6) intrinsic limits of the ventilator (noisy machines that limit physical examination and the recognition of pneumothorax, endobronchial intubation, and endotracheal tube dislodgement). ${ }^{56}$

\section{Current Evidence}

The use of HFOV for the treatment of adult patients with ARDS remains controversial. In the early 2000s, some centers proposed HFOV as a first-line strategy in patients with early ARDS based on encouraging preclinical and clinical data. Three RCTs originally reported an improvement in both oxygenation and overall survival in adult ARDS subjects treated with this approach (Table 2).57-59

A meta-analysis of 8 RCTs suggested a significant mortality benefit for HFOV, but given the relatively small sample sizes and heterogeneous ventilatory strategies used in the control groups, this result was more hypothesisgenerating than definitive evidence for HFOV in ARDS. ${ }^{63}$ These encouraging results were dampened, however, by the results of 2 large RCTs of ARDS subjects treated with HFOV compared with conventional mechanical ventilation: Oscillation in Acute Respiratory Distress Syndrome (OSCAR) and Oscillation for Acute Respiratory Distress Syndrome Treated Early (OSCILLATE). ${ }^{61,62}$ Although the OSCILLATE study was specifically designed to compare HFOV with strict low $\mathrm{V}_{\mathrm{T}}$ and high levels of PEEP in early moderate ARDS, the OSCAR trial was designed to be more pragmatic, comparing HFOV with usual care. The OSCILLATE study, a multi-center trial carried out mainly in North America, planned to enroll 1,200 subjects, but was terminated early for increased mortality ( $47 \%$ vs $35 \%$, $P=.005)$ and worse secondary outcomes (eg, increased need for vasoactive drugs) in the HFOV group. However, the OSCAR trial was performed in the United Kingdom, recruited 795 subjects (mostly from centers without any experience in HFOV), and found no significant difference in mortality $(41.7 \%$ vs $41.1 \%, P=.85)$ between the 2 groups. An updated meta-analysis of 6 RCTs (1,608 subjects), including OSCAR and OSCILLATE, confirmed that HFOV does not significantly reduce mortality, despite leading to an improvement in oxygenation. ${ }^{64}$ As such, HFOV cannot currently be recommended for routine use in adult patients with early moderate-to-severe ARDS.

\section{State of the Art and Future Prospects}

A number of hypotheses have been put forth to explain the negative results seen in OSCAR and OSCILLATE. One of the main limitations of the OSCAR trial was that it was planned as a pragmatic study, leading to the involvement of centers without significant HFOV experience, which could have had a significant effect on the outcomes. 


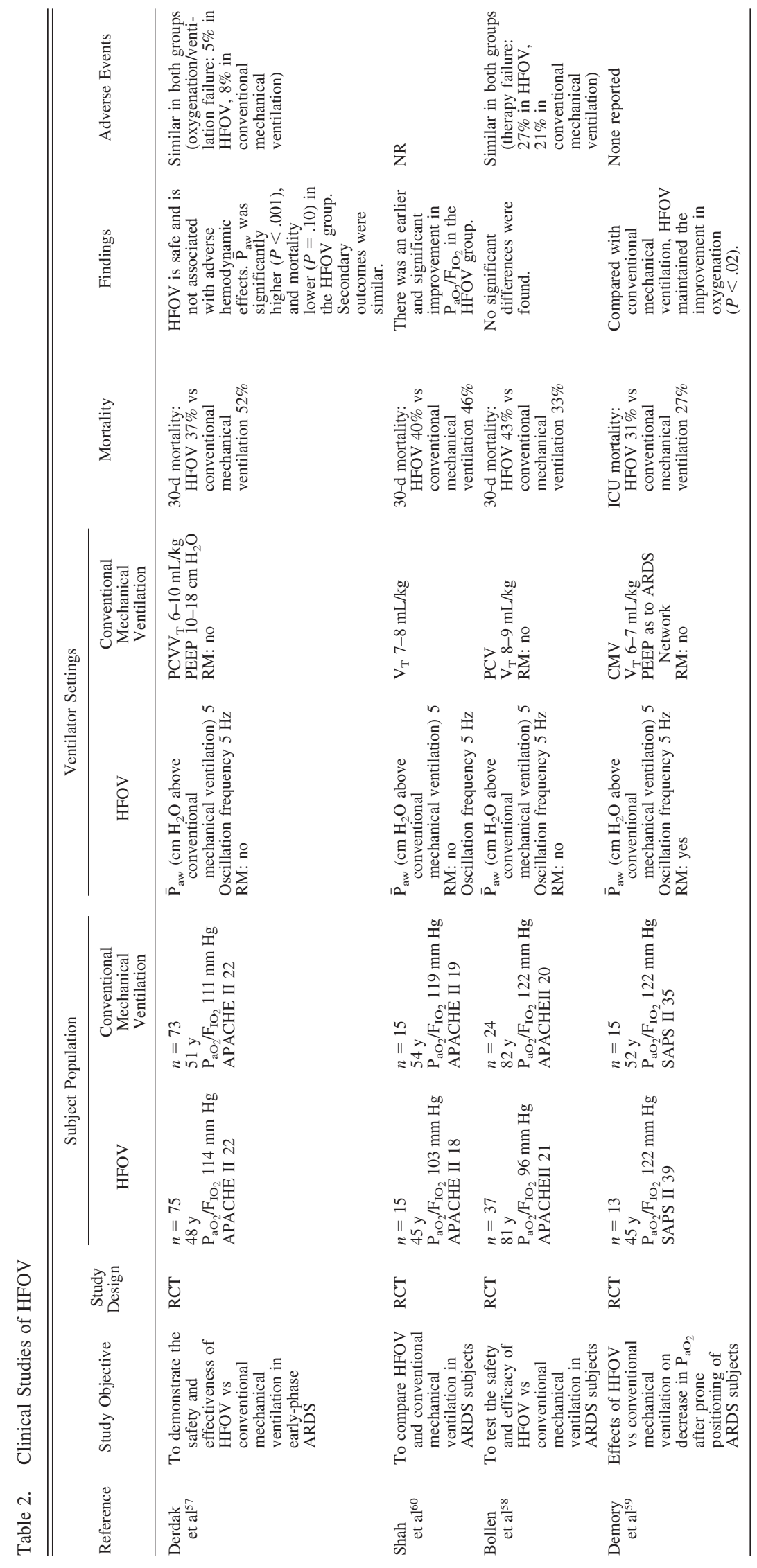




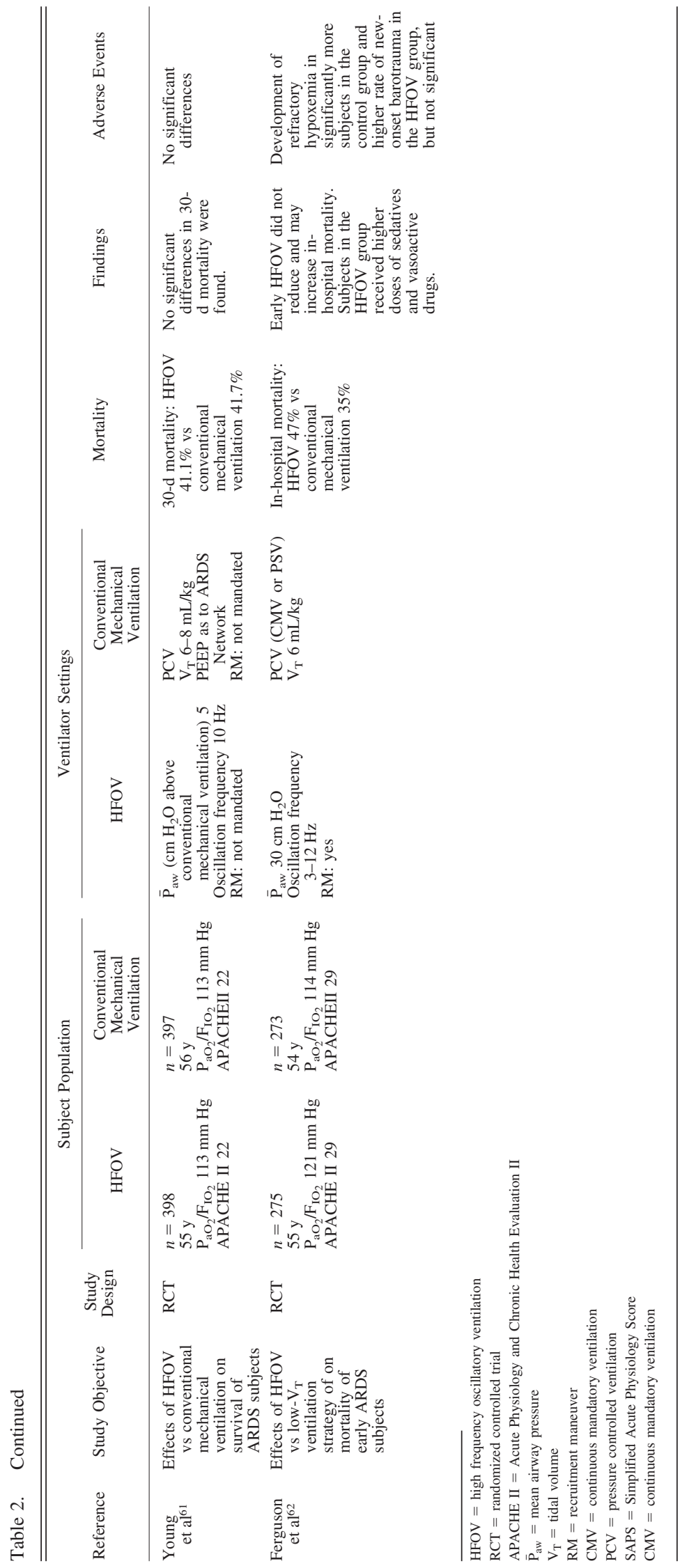




\section{APRV and HFOV to Treat Severe Hypoxemia and Prevent VILI}

Moreover, it did not provide strict protocols to study centers, especially for the conventional ventilation group. This resulted in the control group being treated with relatively low PEEP levels (mean $\pm \mathrm{SD}$ of $11.4 \pm 3.6 \mathrm{~cm} \mathrm{H}_{2} \mathrm{O}$ ) and a relatively high $\mathrm{V}_{\mathrm{T}}$ (mean $\pm \mathrm{SD}$ of $8.3 \pm 2.9 \mathrm{~mL} / \mathrm{kg}$ of predicted body weight), which may have resulted in greater VILI and affected outcomes. In contrast, the conventional arm from the OSCILLATE study was treated according to a strict protocol of low $\mathrm{V}_{\mathrm{T}}$ and high PEEP, and this could partially explain the difference in mortality in the 2 control groups (OSCAR 41\% vs OSCILLATE 35\%). As for the HFOV strategy, excessive $\overline{\mathrm{P}}_{\mathrm{aw}}$ may have produced overdistention, especially in non-recruitable lungs, thus impairing venous return and right ventricular function. ${ }^{65} \mathrm{Com}-$ pared with the OSCILLATE study, the lack of important hemodynamic compromise in OSCAR may have been due to lower applied ventilatory pressures. These hemodynamic side effects could have been increased in the OSCILLATE trial by the administration of sedative drugs and/or neuromuscular blockers to avoid ventilator asynchrony (however, in both trials, the subjects in the HFOV groups received more sedatives and neuromuscular blockers than those in the control groups).

In conclusion, HFOV is not indicated for the routine treatment of adult patients with moderate ARDS. However, it can still be considered as a rescue therapy in ARDS patients with refractory hypoxemia and in selected cases of severe ARDS. Physiological predictors of survival should be considered ${ }^{66}$ : early changes in arterial oxygenation may identify patients with a greater proportion of recruitable lung, who are more likely to benefit from HFOV, whereas patients who require significant increases in vasopressors or with no improvement in oxygenation should be switched back to conventional mechanical ventilation. Although selected patients with severe ARDS may benefit from HFOV, $\mathrm{Gu}$ et $\mathrm{al}^{64}$ pointed out in a recent meta-analysis that these patients are rare and difficult to identify. Future studies will have to consider a new approach to the use of this ventilatory strategy in subjects with ARDS. For example, HFOV may be set according to individual physiology: this may help to induce lung recruitment, thus avoiding tidal overdistention and hemodynamic impairment. The assessment of transpulmonary pressure by measuring esophageal pressure may represent a valid strategy to adopt more physiological $\overline{\mathrm{P}}_{\mathrm{aw}}$. The identification of the optimal $\overline{\mathrm{P}}_{\mathrm{aw}}$ using transpulmonary pressure may reduce the risk of further lung injury, leading to maximal lung recruitment and minimal overdistention. In addition, the use of noninvasive bedside monitoring techniques such as electrical impedance tomography, lung ultrasound, and transthoracic echocardiogram may allow the distinction between lung recruitment and tidal overdistention at different ventilator settings. This can in turn help clinicians adopt the best ventilator settings, thus limiting pulmonary and hemody- namic complications. The Esophageal Pressure-Guided Optimal PEEP/mPaw in CMV and HFOV (EPOCH) Study protocol (ClinicalTrials.gov NCT02342756) is using this type of approach to adjust PEEP during conventional mechanical ventilation and $\overline{\mathrm{P}}_{\mathrm{aw}}$ during HFOV. This pilot study is assessing the safety and feasibility of this method of individualized ventilation with HFOV and is a first step to the many unanswered questions concerning the best mechanical ventilatory strategy based on PEEP and HFOV.

\section{Future Directions and Conclusions}

HFOV and APRV are both open-lung strategies that fulfill the principles of lung-protective ventilation designed to reduce and prevent VILI. They can induce and maintain alveolar recruitment by increasing the resting end-expiratory volume through the use of higher $\overline{\mathrm{P}}_{\mathrm{aw}}$. Despite these common aims, HFOV and APRV differ in several aspects. HFOV typically requires heavy sedation, analgesia, and neuromuscular blockade and is thus particularly indicated for patients early in the course of severe ARDS, where they may benefit from the lack of spontaneous breathing efforts. By contrast, APRV is designed to allow spontaneous breathing (with all of the advantages listed above) and may be less appropriate for the early phases of severe ARDS. Therefore, it is worth considering the use of these strategies serially: HFOV in the early course of the disease, when patients need to be deeply sedated, and APRV at a later stage to support a reduction in sedative and analgesic agents, facilitate spontaneous breathing, improved patient tolerance to the ventilator, and assist in weaning from mechanical ventilation.

As a general rule, the ventilatory management of ARDS should take into consideration the patient's specific physiological parameters, with the objective of providing the greatest benefit with the least risk of complications. Although low- $\mathrm{V}_{\mathrm{T}}$ ventilation with higher PEEP has led to improved outcomes in ARDS, mortality rates remain high, and the optimal ventilatory strategy has yet to be found. It is conceivable that open-lung strategies, such as APRV and HFOV, may play a role in the treatment of early ARDS, but their effects on lung recruitment and physiology need to be closely monitored. In this context, emerging bedside techniques are becoming increasingly important to personalize ventilatory strategies in ICU patients. Lung ultrasound and electrical impedance tomography can accurately assess lung recruitment during ventilation and help avoid alveolar overdistention. Transthoracic echocardiography is also becoming more important to assess the hemodynamic effects (eg, on the right ventricle) of mechanical ventilation. The use of these bedside monitoring techniques and strategies such as APRV and HFOV may allow the safer and more efficacious delivery of these 


\section{APRV and HFOV to Treat Severe Hypoxemia and Prevent VILI}

ventilatory strategies, with the potential for important benefits in patients with ARDS.

In conclusion, rigorous clinical trials are needed to assess the optimal timing, settings, and patient population for APRV and HFOV to understand their place in the therapeutic armamentarium for severe ARDS. Until then, these ventilatory strategies should not be employed routinely in patients with severe ARDS, but may be considered by clinicians on a case-by-case basis and in the context of a clinical trial.

\section{REFERENCES}

1. ARDS Definition Task Force, Ranieri VM, Rubenfeld GD, Thompson BT, Ferguson ND, Caldwell E, et al. Acute respiratory distress syndrome: the Berlin Definition. JAMA 2012;307(23):2526-2533.

2. Gattinoni L, Pesenti A. The concept of "baby lung." Intensive Care Med 2005;31(6):776-784.

3. Tremblay LN, Slutsky AS. Ventilator-induced lung injury: from the bench to the bedside. Intensive Care Med 2006;32(1):24-33.

4. Ranieri VM, Suter PM, Tortorella C, De Tullio R, Dayer JM, Brienza A, et al. Effect of mechanical ventilation on inflammatory mediators in patients with acute respiratory distress syndrome: a randomized controlled trial. JAMA 1999;282(1):54-61.

5. American Thoracic Society, European Society of Intensive Care Medicine, Societé de Réanimation de Langue Française. International Consensus Conferences in Intensive Care Medicine: ventilator-associated lung injury in ARDS. Am J Respir Crit Care Med 1999; 160(6):2118-2124.

6. Slutsky AS, Ranieri VM. Ventilator-induced lung injury. N Engl J Med 2013;369(22):2126-2136.

7. Rouby JJ, Brochard L. Tidal recruitment and overinflation in acute respiratory distress syndrome: yin and yang. Am J Respir Crit Care Med 2007;175(2):104-106.

8. Fan E, Needham DM, Stewart TE. Ventilatory management of acute lung injury and acute respiratory distress syndrome. JAMA 2005; 294(22):2889-2896

9. The Acute Respiratory Distress Syndrome Network. Ventilation with lower tidal volumes as compared with traditional tidal volumes for acute lung injury and the acute respiratory distress syndrome. $\mathrm{N}$ Engl J Med 2000;342(18):1301-1308.

10. Terragni PP, Rosboch G, Tealdi A, Corno E, Menaldo E, Davini O, et al. Tidal hyperinflation during low tidal volume ventilation in acute respiratory distress syndrome. Am J Respir Crit Care Med 2007;175(2):160-166.

11. Amato MB, Barbas CS, Medeiros DM, Schettino Gde P, Lorenzi Filho G, Kairalla RA, et al. Beneficial effects of the "open lung approach" with low distending pressures in acute respiratory distress syndrome. A prospective randomized study on mechanical ventilation. Am J Respir Crit Care Med 1995;152(6 Pt 1):1835-1846.

12. Amato MB, Barbas CS, Medeiros DM, Magaldi RB, Schettino GP, Lorenzi-Filho G, et al. Effect of a protective-ventilation strategy on mortality in the acute respiratory distress syndrome. N Engl J Med 1998;338(6):347-354.

13. Stawicki SP, Goyal M, Sarani B. High-frequency oscillatory ventilation (HFOV) and airway pressure release ventilation (APRV): a practical guide. J Intensive Care Med 2009;24(4):215-229.

14. Downs JB, Stock MC. Airway pressure release ventilation: a new concept in ventilatory support. Crit Care Med 1987;15(5):459-461.

15. Stock MC, Downs JB, Frolicher DA. Airway pressure release ventilation. Crit Care Med 1987;15(5):462-466.
16. Habashi NM. Other approaches to open-lung ventilation: airway pressure release ventilation. Crit Care Med 2005;33(3 Suppl):S228S240.

17. Daoud EG. Airway pressure release ventilation. Ann Thorac Med 2007;2(4):176-179.

18. Neumann P, Golisch W, Strohmeyer A, Buscher H, Burchardi H, Sydow M. Influence of different release times on spontaneous breathing pattern during airway pressure release ventilation. Intensive Care Med 2002;28(12):1742-1749.

19. Putensen C, Muders T, Varelmann D, Wrigge H. The impact of spontaneous breathing during mechanical ventilation. Curr Opin Crit Care 2006;12(1):13-18.

20. Shanholtz C, Brower R. Should inverse ratio ventilation be used in adult respiratory distress syndrome? Am J Respir Crit Care Med 1994;149(5):1354-1358.

21. Sydow M, Burchardi H, Ephraim E, Zielmann S, Crozier TA. Longterm effects of two different ventilatory modes on oxygenation in acute lung injury. Comparison of airway pressure release ventilation and volume-controlled inverse ratio ventilation. Am J Respir Crit Care Med 1994;149(6):1550-1556.

22. Putensen C, Mutz NJ, Putensen-Himmer G, Zinserling J. Spontaneous breathing during ventilatory support improves ventilation-perfusion distributions in patients with acute respiratory distress syndrome. Am J Respir Crit Care Med 1999;159(4 Pt 1):1241-1248.

23. Putensen C, Zech S, Wrigge H, Zinserling J, Stüber F, Von Spiegel $\mathrm{T}$, Mutz N. Long-term effects of spontaneous breathing during ventilatory support in patients with acute lung injury. Am J Respir Crit Care Med 2001;164(1):43-49.

24. Wrigge H, Zinserling J, Neumann P, Muders T, Magnusson A, Putensen C, Hedenstierna G. Spontaneous breathing with airway pressure release ventilation favors ventilation in dependent lung regions and counters cyclic alveolar collapse in oleic-acid-induced lung injury: a randomized controlled computed tomography trial. Crit Care 2005;9(6):R780-R789.

25. Fan E, Khatri P, Mendez-Tellez PA, Shanholtz C, Needham DM. Review of a large clinical series: sedation and analgesia usage with airway pressure release and assist-control ventilation for acute lung injury. J Intensive Care Med 2008;23(6):376-383.

26. Kaplan LJ, Bailey H, Formosa V. Airway pressure release ventilation increases cardiac performance in patients with acute lung injury/adult respiratory distress syndrome. Crit Care 2001;5(4):221226.

27. Testerman GM, Breitman I, Hensley S. Airway pressure release ventilation in morbidly obese surgical patients with acute lung injury and acute respiratory distress syndrome. Am Surg 2013;79(3):242246.

28. Mehta S, Burry L, Fischer S, Martinez-Motta JC, Hallett D, Bowman $\mathrm{D}$, et al. Canadian survey of the use of sedatives, analgesics, and neuromuscular blocking agents in critically ill patients. Crit Care Med 2006;34(2):374-380.

29. Papazian L, Forel JM, Gacouin A, Penot-Ragon C, Perrin G, Loundou A, et al. Neuromuscular blockers in early acute respiratory distress syndrome. N Engl J Med 2010;363(12):1107-1116.

30. Richard JC, Lyazidi A, Akoumianaki E, Mortaza S, Cordioli RL, Lefebvre JC, et al. Potentially harmful effects of inspiratory synchronization during pressure preset ventilation. Intensive Care Med 2013;39(11):2003-2010.

31. Daoud EG, Farag HL, Chatburn RL. Airway pressure release ventilation: what do we know? Respir Care 2012;57(2):282-292.

32. Varpula T, Jousela I, Niemi R, Takkunen O, Pettilä V. Combined effects of prone positioning and airway pressure release ventilation on gas exchange in patients with acute lung injury. Acta Anaesth Scand 2003;47(5):516-524. 


\section{APRV and HFOV to Treat Severe Hypoxemia and Prevent VILI}

33. Varpula T, Valta P, Niemi R, Takkunen O, Hynynen M, Pettilä VV. Airway pressure release ventilation as a primary ventilatory mode in acute respiratory distress syndrome. Acta Anaesth Scand 2004;48(6): 722-731.

34. Dart BW 4th, Maxwell RA, Richart CM, Brooks DK, Ciraulo DL, Barker DE, Burns RP. Preliminary experience with airway pressure release ventilation in a trauma/surgical intensive care unit. J Trauma 2005;59(1):71-76.

35. Yoshida T, Rinka H, Kaji A, Yoshimoto A, Arimoto H, Miyaichi T, Kan M. The impact of spontaneous ventilation on distribution of lung aeration in patients with acute respiratory distress syndrome: airway pressure release ventilation versus pressure support ventilation. Anesth Analg 2009;109(6):1892-1900.

36. González M, Arroliga AC, Frutos-Vivar F, Raymondos K, Esteban $\mathrm{A}$, Putensen $\mathrm{C}$, et al. Airway pressure release ventilation versus assist-control ventilation: a comparative propensity score and international cohort study. Intensive Care Med 2010;36(5):817-827.

37. Maxwell RA, Green JM, Waldrop J, Dart BW, Smith PW, Brooks D, et al. A randomized prospective trial of airway pressure release ventilation and low tidal volume ventilation in adult trauma patients with acute respiratory failure. J Trauma 2010;69(3):501-510; discussion 511.

38. Maung AA, Schuster KM, Kaplan LJ, Ditillo MF, Piper GL, Maerz LL, et al. Compared to conventional ventilation, airway pressure release ventilation may increase ventilator days in trauma patients. J Trauma Acute Care Surg 2012;73(2):507-510.

39. Ware LB. Prognostic determinants of acute respiratory distress syndrome in adults: impact on clinical trial design. Crit Care Med 2005; 33(3 Suppl):S217-S222.

40. Rose L, Hawkins M. Airway pressure release ventilation and biphasic positive airway pressure: a systematic review of definitional criteria. Intensive Care Med 2008;34(10):1766-1773.

41. Garner W, Downs JB, Stock MC, Räsänen J. Airway pressure release ventilation (APRV). A human trial. Chest 1988;94(4):779-781.

42. Bryan AC. The oscillations of HFO. Am J Respir Crit Care Med 2001;163(4):816-817.

43. Froese AB, Kinsella JP. High-frequency oscillatory ventilation: lessons from the neonatal/pediatric experience. Crit Care Med 2005; 33(3 Suppl):S115-S121.

44. Goffi A, Ferguson ND. High-frequency oscillatory ventilation for early acute respiratory distress syndrome in adults. Curr Opin Crit Care 2014;20(1):77-85.

45. Hager DN, Fessler HE, Kaczka DW, Shanholtz CB, Fuld MK, Simon BA, Brower RG. Tidal volume delivery during high-frequency oscillatory ventilation in adults with acute respiratory distress syndrome. Crit Care Med 2007;35(6):1522-1529.

46. Fessler HE, Derdak S, Ferguson ND, Hager DN, Kacmarek RM, Thompson BT, Brower RG. A protocol for high-frequency oscillatory ventilation in adults: results from a roundtable discussion. Crit Care Med 2007;35(7):1649-1654.

47. Ferguson ND, Chiche JD, Kacmarek RM, Hallett DC, Mehta S, Findlay GP, et al. Combining high-frequency oscillatory ventilation and recruitment maneuvers in adults with early acute respiratory distress syndrome: the Treatment with Oscillation and an Open Lung Strategy (TOOLS) Trial pilot study. Crit Care Med 2005;33(3):479486.

48. Tobin MJ. Principles and practice of mechanical ventilation. New York: McGraw-Hill Medical Publishing Division; 2006.
49. Slutsky AS, Drazen JM. Ventilation with small tidal volumes. N Engl J Med 2002;347(9):630-631.

50. Chang HK. Mechanisms of gas transport during ventilation by highfrequency oscillation. J Appl Physiol 1984;56(3):553-563.

51. Imai Y, Slutsky AS. High-frequency oscillatory ventilation and ventilator-induced lung injury. Crit Care Med 2005;33(3 Suppl):S129S134.

52. Day R, Goodfellow AM, Apgar V, Beck GJ. Pressure-time relations in safe correction of atelectasis in animal lungs. Pediatrics 1952; 10(5):593-602.

53. Froese AB. High-frequency oscillatory ventilation for adult respiratory distress syndrome: let's get it right this time! Crit Care Med 1997;25(6):906-908

54. Pillow JJ. Tidal volume, recruitment and compliance in HFOV: same principles, different frequency. Eur Respir J 2012;40(2):291-293.

55. Tsuzaki K, Hales CA, Strieder DJ, Venegas JG. Regional lung mechanics and gas transport in lungs with inhomogeneous compliance. J Appl Physiol 1993;75(1):206-216.

56. Novelo J. High frequency oscillatory ventilation (HFOV) generates potentially harmful noise in a medical intensive care unit. Chest 2012;142(4_MeetingAbstracts):949A.

57. Derdak S, Mehta S, Stewart TE, Smith T, Rogers M, Buchman TG, et al. High-frequency oscillatory ventilation for acute respiratory distress syndrome in adults: a randomized, controlled trial. Am J Respir Crit Care Med 2002;166(6):801-808.

58. Bollen CW, van Well GT, Sherry T, Beale RJ, Shah S, Findlay G, et al. High frequency oscillatory ventilation compared with conventional mechanical ventilation in adult respiratory distress syndrome: a randomized controlled trial [ISRCTN24242669]. Crit Care 2005; 9(4):R430-R439.

59. Demory D, Michelet P, Arnal JM, Donati S, Forel JM, Gainnier M, et al. High-frequency oscillatory ventilation following prone positioning prevents a further impairment in oxygenation. Crit Care Med 2007;35(1):106-111

60. Shah SB, Findlay GP, Jackson SK, Smithies MN. Prospective study comparing HFOV versus CMV in patients with ARDS. Intensive Care Med 2004;30:S84.

61. Young D, Lamb SE, Shah S, MacKenzie I, Tunnicliffe W, Lall R, et al. High-frequency oscillation for acute respiratory distress syndrome. N Engl J Med 2013;368(9):806-813.

62. Ferguson ND, Cook DJ, Guyatt GH, Mehta S, Hand L, Austin P, et al. High-frequency oscillation in early acute respiratory distress syndrome. N Engl J Med 2013;368(9):795-805.

63. Sud S, Sud M, Friedrich JO, Meade MO, Ferguson ND, Wunsch H, Adhikari NK. High frequency oscillation in patients with acute lung injury and acute respiratory distress syndrome (ARDS): systematic review and meta-analysis. BMJ 2010;340:c2327.

64. Gu XL, Wu GN, Yao YW, Shi DH, Song Y. Is high-frequency oscillatory ventilation more effective and safer than conventional protective ventilation in adult acute respiratory distress syndrome patients? A meta-analysis of randomized controlled trials. Crit Care 2014;18(3):R111

65. Malhotra A, Drazen JM. High-frequency oscillatory ventilation on shaky ground. N Engl J Med 2013;368(9):863-865.

66. Camporota L, Sherry T, Smith J, Lei K, McLuckie A, Beale R. Physiological predictors of survival during high-frequency oscillatory ventilation in adults with acute respiratory distress syndrome. Crit Care 2013;17(2):R40. 